Research Paper

\title{
Analysis of Efficacy Differences between Caudal and Lumbar Interlaminar Epidural Injections in Chronic Lumbar Axial Discogenic Pain: Local Anesthetic Alone vs. Local Combined with Steroids
}

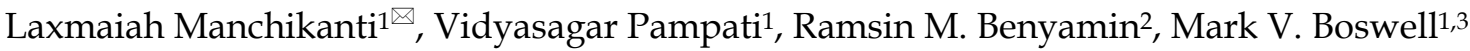 \\ 1. The Pain Management Center of Paducah, Paducah, KY, USA. \\ 2. Millennium Pain Center, Bloomington, College of Medicine, University of Illinois, Urbana-Champaign, IL, USA. \\ 3. Department of Anesthesiology and Perioperative Medicine, University of Louisville, Louisville, KY, USA.
}

$\square$ Corresponding author: Laxmaiah Manchikanti, M.D. 2831 Lone Oak Road, Paducah, Kentucky 42003. Phone: 270-554-8373 Ext. 101 E-mail: drlm@thepainmd.com.

() 2015 Ivyspring International Publisher. Reproduction is permitted for personal, noncommercial use, provided that the article is in whole, unmodified, and properly cited. See http://ivyspring.com/terms for terms and conditions.

Received: 2014.10.21; Accepted: 2014.12.30; Published: 2015.01.20

\begin{abstract}
Study Design: Comparative assessment of randomized controlled trials of caudal and lumbar interlaminar epidural injections in chronic lumbar discogenic pain.

Objective: To assess the comparative efficacy of caudal and lumbar interlaminar approaches of epidural injections in managing axial or discogenic low back pain.

Summary of Background Data: Epidural injections are commonly performed utilizing either a caudal or lumbar interlaminar approach to treat chronic lumbar axial or discogenic pain, which is pain exclusive of that associated with a herniated intervertebral disc, or that is due to degeneration of the zygapophyseal joints, or due to dysfunction of the sacroiliac joints, respectively. The literature on the efficacy of epidural injections in managing chronic axial lumbar pain of presumed discogenic origin is limited.

Methods: The present analysis is based on 2 randomized controlled trials of chronic axial low back pain not caused by disc herniation, radiculitis, or facet joint pain, utilizing either a caudal or lumbar interlaminar approach, with a total of 240 patients studied, and a 24-month follow-up. Patients were assigned to receive either local anesthetic only or local anesthetic with a steroid in each 60 patient group.

Results: The primary outcome measure was significant improvement, defined as pain relief and functional status improvement of at least $50 \%$ from baseline, which was reported at 24-month follow-ups in $72 \%$ who received local anesthetic only with a lumbar interlaminar approach and $54 \%$ who received local anesthetic only with a caudal approach. In patients receiving local anesthetic with a steroid, the response rate was $67 \%$ for those who had a lumbar interlaminar approach and $68 \%$ for those who had a caudal approach at 12 months. The response was significantly better in the lumbar interlaminar group who received local anesthetic only, $77 \%$ versus $56 \%$ at 12 months and $72 \%$ versus $54 \%$ at 24 months.

Conclusion: This assessment shows that in patients with axial or discogenic pain in the lumbar spine after excluding facet joint and SI Joint pain, epidural injections of local anesthetic by the caudal or lumbar interlaminar approach may be effective in managing chronic low back pain with a potential superiority for a lumbar interlaminar approach over a caudal approach.
\end{abstract}

Key words: Chronic low back pain, axial low back pain, lumbar discogenic pain, caudal epidural injections, lumbar interlaminar epidural injections. 


\section{Introduction}

Low back pain is a major disabling condition that has a substantial social, economic, and health care impact and is increasing in prevalence [1-16]. An assessment by the US Burden of Disease Collaborators reported low back pain as the number one cause of disability [1]. Even though modalities for managing chronic low back pain continue to increase, the accurate cause of low back pain is determined in a very small proportion of patients, with disc herniation and spinal stenosis contributing to pain in a minority of patients, identified with ease and managed with therapies based on moderate evidence $[4,17,18]$. A multitude of treatment modalities, including surgical interventions, conservative modalities, chiropractic therapy, drug therapy, and interventional therapies continue to increase at a pace considered as uncontrollable, with escalating health care costs associated with numerous complications and the failure of some therapies [4, 6-19]. The accurate cause of low back pain is not determined in the majority of patients and in the cases where it is determined, costs, disability, and failed therapies are escalating.

\section{Pathophysiology}

The intervertebral disc has long been considered a common source of low back pain with pain caused by disc herniation or with pain emanating from pathologic changes within the disc itself [4, 20-23]. Discogenic pain was proposed even earlier than disc herniation with reports of discogenic pain published in 1932 and disc herniation in 1934 [20, 24, 25]. Pain originating from intervertebral discs without disc herniation has been described as discogenic pain, internal disc disruption, and painful degenerative disc disease [20-23]. However, discogenic pain has been poorly defined and its existence itself is being questioned with rather exceedingly controversial diagnostic and treatment modalities [4, 6-8, 10, 11, 14-16, 26-31]. Debate and controversies in reference to discogenic pain and its management are based on a lack of consensus on the definition of discogenic pain itself, poor prognosis with expensive surgical care, a lack of extensive published data from nonsurgical care, and the escalating utilization of multiple modalities and overall health care costs $[4,6-8,10,11,14-16$, 26-31].

While intervertebral disc degeneration is an age-related process that is asymptomatic in most individuals, pathologic degeneration can be a major source of pain and disability [4, 20-22]. "Discogenic low back pain" refers specifically to the pain caused by internal disc disruption (IDD) as proposed by Crock [32] as a condition marked by alteration in the internal structure and metabolic functions of the intervertebral disc. However, discogenic pain also has been described as a separate entity [20-22]. Consequently, the prevalence of pain due to IDD was reported to be $39 \%$ and $42 \%$ in patients suffering with chronic low back pain[33, 34], in contrast to primary lumbar discogenic pain which was reported in $26 \%$ when no other cause was suspected [35]. Peng et al [21] assessed the natural history of discogenic low back pain with IDD in 156 patients which constituted $56 \%$ of the sample and showed $87 \%$ of the patients continued their symptoms or suffered with additional symptoms.

Debate not only exists concerning the diagnosis, but also with therapeutic modalities. There have been dismal results with various surgical and nonsurgical interventions and a natural history of discogenic pain which continues to be present even 4 years after the failure of conservative management modalities [20-22].

\section{Epidural Injections}

Epidural injections for managing chronic axial or discogenic pain is not well established and not well-known, but continually debated and appears to be one of the most common interventions performed for managing axial low back pain without disc herniation[4, 10, 11, 14-16, 20, 36-38]. The evidence continues to emerge in reference to the role of epidural injections for managing axial or discogenic low back pain. In the past, multiple studies included patients without separating disc herniation from discogenic pain as well as without eliminating facet joint pain or sacroiliac joint pain, which has led to an inordinately high failure rate. As an alternative to surgical fusion or intradiscal therapies, epidural injections have been proposed [36-38]. Their effectiveness has been demonstrated in randomized controlled trials and systematic reviews [4, 10, 11, 14-16, 20, 36-38]. However, care must be taken to exclude patients with facet joint or sacroiliac joint pain. Manchikanti et al $[36,37]$, in 2 randomized controlled trials with 120 patients in each trial, reported significant improvement as defined by the criteria of $50 \%$ or more reduction in pain scores and improvement in functional status.

\section{Objectives}

Comparative studies are not available on the various approaches for managing chronic lumbar discogenic pain after ruling out facet joint and sacroiliac joint pain. We sought to evaluate the efficacy of the caudal and lumbar interlaminar approaches of epidural injections in managing chronic, intractable, persistent axial or discogenic low back pain after ruling out facet joint and sacroiliac joint pain and after 
partial or no response to conservative management with a 2-year follow-up, utilizing 2 published randomized trials with identical protocols $[36,37]$.

\section{Materials and Methods}

This assessment was performed from 2 previously published randomized controlled trials [36, 37] conducted in a tertiary referral interventional pain management center in the United States by the same group of investigators utilizing identical protocols. The trials $[36,37]$ and this analysis were conducted with internal resources. Institutional Review Board approval was obtained for both trials and they were registered with the US Clinical Trial Registry with assigned numbers of National Clinical Trial (NCT) NCT00370799 and NCT00681447. The trials were conducted based on Consolidated Standards of Reporting Trials guidance.

Both manuscripts $[36,37]$ included in this analysis have described in detail the patients, pre-enrollment assessment results, interventions, inclusion and exclusion criteria, description of interventions, additional and cointerventions, objectives and outcomes, randomization, sequence generation, allocation concealment, implementation, blinding, sample size calculation, and appropriate statistical methodology. All the patients who participated in these trials were recruited from a practice that provides interventional pain management services. Salient features are described below.

\section{Interventions}

The protocols specified caudal and lumbar interlaminar epidural injections. The patients in both trials were divided into 60 patients in each group who received either local anesthetic only or local anesthetic with a steroid. For caudal epidural injections, a total of $10 \mathrm{~mL}$ of solution $(10 \mathrm{~mL}$ of $0.5 \%$ lidocaine or $9 \mathrm{~mL}$ of lidocaine with $1 \mathrm{~mL}$ of steroid) and for lumbar interlaminar epidural injections, a total of $6 \mathrm{~mL}$ of solution $(6 \mathrm{~mL}$ of $0.5 \%$ lidocaine or $5 \mathrm{~mL}$ of lidocaine with $1 \mathrm{~mL}$ of steroid) were injected.

\section{Inclusion and Exclusion Criteria}

Inclusion criteria focused on chronic lumbar axial or discogenic pain without disc herniation, radiculitis, facet joint pain, or sacroiliac joint pain in patients over 18 years of age with at least 6 months of function-limiting low back pain. The facet joint pain and sacroiliac joint pain were ruled out by controlled comparative local anesthetic blocks [4, 33-35, 39-42], whereas disc herniation was excluded by radiologic investigations and clinical assessment.

Exclusion criteria included previous lumbar surgery, central or foraminal spinal stenosis, radiculi- tis without disc herniation, facet joint pain, and sacroiliac joint pain.

\section{Description of Interventions}

All the procedures were performed in a sterile operating room under fluoroscopy by one physician with appropriate monitoring and intravenous sedation as indicated. Caudal epidural injections were performed by entering the epidural space through the sacral hiatus confirmed by contrast medium injection; whereas, lumbar interlaminar epidural injections were performed with the loss of resistance technique and confirmed under fluoroscopy with contrast medium injection.

\section{Outcomes}

Outcome measurements were carried out at various periods up to 24 months with significant improvement defined as at least $50 \%$ improvement in pain relief and functional status.

The Numeric Pain Rating Scale (NRS) and Oswestry Disability Index (ODI), both of which are validated measures, were utilized in these trials [36, 37].

\section{Sample Size}

A sample size was determined for both randomized trials. A total of 110 patients, 55 patients in each group for each trial, were required. Considering a 0.05 , 2-sided significance level, a power of $80 \%$, an allocation ratio of 1:1, and accounting for a possible $10 \%$ attrition/noncompliance rate, 120 patients were included in each trial $[36,37]$.

\section{Statistical Analysis}

The Statistical Package for Social Sciences version 9.01 (SPSS Inc, Chicago, IL) was utilized. Chi-square (Fisher's exact test where necessary) and $t$ test were used for categorical and continuous data comparison, respectively. Patients' outcomes were measured at 6 points in time, thus a repeated measures analysis of variance was performed with a post hoc analysis Bonferroni correction. A $P$ value of less than 0.05 was considered significant.

An intent-to-treat analysis was performed after a sensitivity analysis in the original trials [36, 37].

\section{Results}

Patient flow is shown in Fig. 1 of both manuscripts [36, 37]. As described in these manuscripts, an intent-to-treat analysis was performed and all 60 patients in each trial were included in the analysis. There was an overall follow-up rate at the end of 2 years of $82 \%$ in the caudal trial and $78 \%$ in the lumbar interlaminar trial. 


\section{Recruitment}

Patients were recruited from January 2007 through August 2008 for the caudal trial [35] and from January 2008 through May 2010 for the lumbar interlaminar trial [37].

\section{Baseline Characteristics}

Baseline demographic and clinical characteristics of each trial are shown in Table 1. There were no statistically significant differences between the caudal and lumbar interlaminar trials except for mean age and ODI scores.

\section{Analysis of Outcomes}

\section{Pain Relief and Functional Assessment}

Table 2 shows the comparative results of outcomes representing the results of repeated measures analysis of both trials over 24 months. There were no significant differences noted either in NRS or ODI scores with local anesthetic only compared to local anesthetic with a steroid or caudal compared to lumbar interlaminar epidurals. There were significant differences with improvement in all parameters from baseline to 24-month follow-up. However, the lumbar interlaminar group fared better when all patients were considered in reference to average total relief for one year and also for 2 years. Further, nonresponsive patients were inordinately high, with 42 in the caudal group, whereas there were only 11 in the lumbar interlaminar group.

Figures 1 and 2 show the proportion of patients with significant improvement in pain and function of at least $50 \%$. As shown in Figure 1, in the responsive patients, when local anesthetic was administered alone, significant improvement was seen in $78 \%$ in the lumbar interlaminar group and $84 \%$ in the caudal group compared to $70 \%$ and $73 \%$ at 24 months in patients who received local anesthetic with a steroid. A comparison of the results in all patients showed improvement with local anesthetic alone in $72 \%$ in the lumbar interlaminar group and $54 \%$ in the caudal group, whereas it was $67 \%$ and $60 \%$ with local anesthetic with a steroid at 24 months. Improvement was in a significantly higher proportion of patients receiving lumbar interlaminar injections of local anesthetic only at 12 months and 24 months.

Table 1. Baseline demographic and clinical characteristics.

\begin{tabular}{|c|c|c|c|c|}
\hline & & Interlaminar (120) & Caudal (120) & $P$ value \\
\hline \multirow[t]{2}{*}{ Gender } & Male & $32 \%(38)$ & $29 \%(35)$ & 0.673 \\
\hline & Female & $68 \%(82)$ & $71 \%(85)$ & \\
\hline Age & Mean \pm SD & $42.0 \pm 11.6$ & $46.2 \pm 14.3$ & 0.013 \\
\hline Weight & Mean \pm SD & $189.9 \pm 55.8$ & $183.3 \pm 51.9$ & 0.344 \\
\hline Height & Mean \pm SD & $66.1 \pm 3.9$ & $65.5 \pm 3.7$ & 0.218 \\
\hline Body Mass Index & Mean \pm SD & $30.5 \pm 8.5$ & $29.9 \pm 7.9$ & 0.599 \\
\hline Duration of Pain (months) & Mean \pm SD & $116.6 \pm 99.4$ & $95.5 \pm 86.0$ & 0.080 \\
\hline \multirow[t]{2}{*}{ Onset of Pain } & Gradual & $68 \%(82)$ & $65 \%(78)$ & 0.681 \\
\hline & Injury & $32 \%(38)$ & $35 \%(42)$ & \\
\hline Numeric Pain Rating Scale Scores & Mean \pm SD & $7.8 \pm 0.9$ & $8.0 \pm 0.9$ & 0.242 \\
\hline Oswestry Disability Index Scores & Mean \pm SD & $29.9 \pm 4.9$ & $28.3 \pm 4.9$ & 0.014 \\
\hline
\end{tabular}

Table 2. Comparative results of Numeric Pain Rating Scale scores and Oswestry Disability Index scores for 2 years (Mean \pm SD) of lumbar interlaminar and caudal epidural injections.

\begin{tabular}{|c|c|c|c|c|}
\hline & \multicolumn{2}{|c|}{ Numeric Pain Rating Scale } & \multicolumn{2}{|c|}{ Oswestry Disability Index } \\
\hline & Interlaminar & Caudal & Interlaminar & Caudal \\
\hline Baseline & $7.8 \pm 0.9$ & $8.0 \pm 0.9$ & $29.9 \pm 4.9$ & $28.3 \pm 4.9$ \\
\hline 3 months & $3.5^{*} \pm 1.0$ & $3.9^{*} \pm 1.6$ & $14.7^{*} \pm 4.7$ & $15.4^{*} \pm 6.5$ \\
\hline 6 months & $3.7^{*} \pm 1.1$ & $3.9^{*} \pm 1.7$ & $14.9^{*} \pm 5.0$ & $15.3^{*} \pm 7.0$ \\
\hline 12 months & $3.7^{*} \pm 1.2$ & $4.1^{*} \pm 1.7$ & $15.0^{*} \pm 5.7$ & $15.4^{*} \pm 6.9$ \\
\hline 18 months & $3.9^{*} \pm 1.3$ & $4.2^{*} \pm 1.8$ & $14.9^{*} \pm 5.5$ & $15.5^{*} \pm 7.1$ \\
\hline 24 months & $3.7^{*} \pm 1.4$ & $4.2^{*} \pm 1.8$ & $14.7^{*} \pm 5.6$ & $15.7^{*} \pm 7.1$ \\
\hline Group Difference & \multicolumn{2}{|c|}{0.240} & \multicolumn{2}{|c|}{0.011} \\
\hline Time Difference & \multicolumn{2}{|c|}{0.001} & \multicolumn{2}{|c|}{0.000} \\
\hline
\end{tabular}

A lower value indicates better condition.

${ }^{*}$ significant difference with baseline values within the group $(P<0.001)$. 


\section{Therapeutic Procedural Characteristics}

Therapeutic procedural characteristics with procedural frequency, average relief per procedure, and average total relief in weeks over a period of 2 years is shown in Table 3. Among the patients who were responsive, lumbar interlaminar and caudal injections both showed over 72 weeks average relief for 2 years compared to all patients who showed approximately 66 weeks in the lumbar interlaminar group and 53 weeks in the caudal group. The average procedures for 2 years was 6 with an average relief per procedure of 11 to 12 weeks. Lumbar interlaminar epidural injections were superior with an average total relief of one year and 2 years compared to caudal injections due to a high nonresponsive rate in the caudal trial.

\section{Adverse Events}

No major adverse events were reported in either trial.

Table 3. Therapeutic procedural characteristics with procedural frequency, average relief per procedure, and average total relief in weeks over a period of 2 years.

\begin{tabular}{|c|c|c|c|c|c|c|}
\hline & \multicolumn{2}{|c|}{ Responsive Patients } & \multicolumn{2}{|c|}{ Nonresponsive Patients } & \multicolumn{2}{|l|}{ All Patients } \\
\hline & Interlaminar (109) & Caudal (78) & Interlaminar (11) & Caudal (42) & Interlaminar (120) & Caudal (120) \\
\hline Average Number of Procedures for One Year & $4.0 \pm 0.9$ & $4.0 \pm 1.0$ & $1.9 \pm 1.2$ & $2.8 \pm 1.5$ & $3.8^{*} \pm 1.1$ & $3.6 \pm 1.3$ \\
\hline Average Number of Procedures for Two Years & $6.4 \pm 2.2$ & $6.1 \pm 2.2$ & $1.9 \pm 1.2$ & $3.1 \pm 2.0$ & $6.0^{*} \pm 2.5$ & $5.0 \pm 2.5$ \\
\hline Average Relief for First procedure & $6.3 \pm 4.1$ & $6.8 \pm 5.4$ & $0.7 \pm 0.9$ & $1.9 \pm 2.3$ & $5.8 \pm 4.2$ & $5.1 \pm 5.1$ \\
\hline Average Relief for Second Procedure & $10.6 \pm 10.5$ & $12.2 \pm 11.6$ & $0.9 \pm 1.0$ & $1.6 \pm 1.9$ & $10.1 \pm 10.5$ & $9.0 \pm 10.9$ \\
\hline After Initial 2 Procedures & $12.7 \pm 3.6(475)$ & $13.4 \pm 7.2(316)$ & $3.2^{*} \pm 3.3(5)$ & $8.7 \pm 5.8(53)$ & $12.6 \pm 3.7(480)$ & $12.7 \pm 7.2(369)$ \\
\hline Average Relief per Procedure & $11.4 \pm 5.8(693)$ & $12.1 \pm 8.2(472)$ & $1.3^{*} \pm 2.0(21)$ & $4.6 \pm 5.3(129)$ & $11.1 \pm 6.0(714)$ & $10.5 \pm 8.2(601)$ \\
\hline Average Total Relief for One Year (Weeks) & $39.3 \pm 12.3$ & $42.0 \pm 9.9$ & $2.5 \pm 4.0$ & $10.1 \pm 12.2$ & $35.9^{*} \pm 15.9$ & $30.8 \pm 18.6$ \\
\hline Average Total Relief for Two Years (Weeks) & $72.2 \pm 29.2$ & $73.0 \pm 28.1$ & $2.5 \pm 4.0$ & $14.3 \pm 22.7$ & $65.8^{*} \pm 34.4$ & $52.9 \pm 38.3$ \\
\hline
\end{tabular}

* - Significant difference with caudal epidurals.

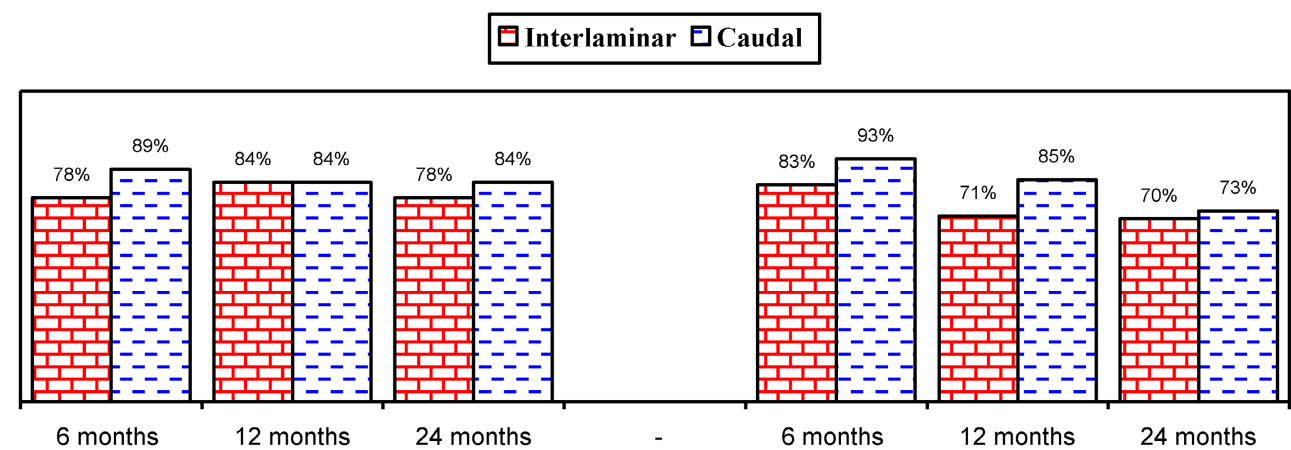

With local anesthetic

With local anesthetic and steroid No significant difference between groups or trials

Figure 1. Illustration of reduction (at least 50\%) in pain rating scores and Oswestry Disability Index scores from baseline (only responsive patients).

\section{OInterlaminar ECaudal}

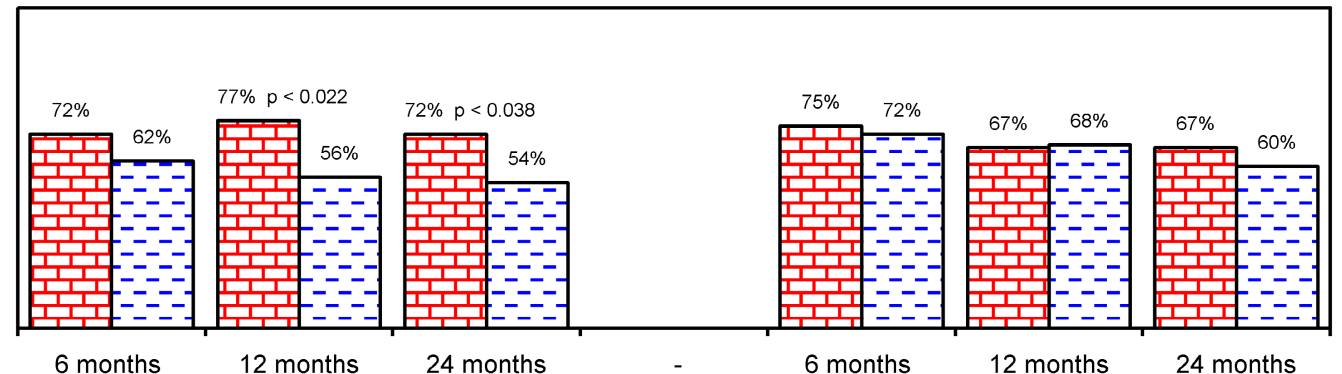

With local anesthetic

With local anesthetic and steroid

Figure 2. Illustration of reduction (at least 50\%) in pain rating scores and Oswestry Disability Index scores from baseline (all patients). 


\section{Discussion}

This analysis shows the efficacy of caudal and lumbar interlaminar epidural injections for managing chronic persistent axial or discogenic pain without disc herniation, facet joint pain, or sacroiliac joint pain at 24 months in $54 \%$ and $60 \%$ of the patients in the caudal group who received local anesthetic only or local anesthetic with a steroid and $72 \%$ and $67 \%$ of the patients in the lumbar interlaminar group who received local anesthetic only or local anesthetic with a steroid. However, when only responsive patients were considered with improvement of at least 3 weeks with the 2 initial procedures, significant improvement was seen in $78 \%$ and $84 \%$ who received local anesthetic only in the lumbar interlaminar and caudal trials; whereas it was $70 \%$ and $73 \%$ for local anesthetic with a steroid. The proportion of patients improving when all patients were considered who received local anesthetic only was higher in the lumbar interlaminar group ( $54 \%$ versus $72 \%$ ), whereas it was similar in patients who received local anesthetic with a steroid, as well as in responsive patients who received local anesthetic only or with a steroid. This may be explained by the fact that 11 , or $9 \%$, of the patients in the lumbar interlaminar group were shown to be nonresponsive, compared to 42 , or $35 \%$, of the patients in the caudal trial. Thus, once patients are judged to be responsive with the initial 2 injections, caudal and lumbar interlaminar epidural injections provide similar results of efficacy. These results also explain that it may be prudent to perform lumbar interlaminar epidural injections at least initially to judge responsiveness or a significant proportion of patients may be judged nonresponsive and may be denied further treatments.

When medically necessary and indicated, epidural injections may be repeated after the pain starts returning and pain relief and functional status improvement start dissipating below the $50 \%$ level in 10 to 12 weeks. Approximately 6 epidural injections per year are indicated in patients who demonstrate significant improvement with the first 2 procedures. These patients are considered to be responsive patients.

While lumbar disc herniation is relatively easily diagnosed and is the most common indication for surgical intervention, diagnosing discogenic pain is poorly defined and the diagnostic methods and treatments are controversial. Similar to disc herniation, the course and prognosis of discogenic pain is considered favorable, and by some, even better, than disc herniation.

Anatomically and pathophysiologically, the normal intervertebral disc is avascular and aneural, except for the outer third of the annulus fibrosis, which is innervated by sensory nerve endings from a dorsal root ganglion (DRG) [20-23]. Nevertheless, as the disc degeneration advances, disc inflammation promotes axonal growth of afferent fibers innervating the disc by secreting proinflammatory mediators, such as tumor necrosis factor and interleukin-6. Further, trophic growth factor for sympathetic and sensory nerve growth factor (NGF) also stimulate the differentiation, growth, maintenance, and survival of sympathetic and sensory nerve cells. NGF has been shown to exert hyperalgesic properties by sensitization of the sensory nerves, stimulation of peripheral nociceptive neurons growing into the intervertebral disc tissues triggering pain signals, and the neurons of DRG transmitting an inflammatory signal from the spinal cord to the pain centers of the brain. This response rate is similar to epidural injections for various conditions in multiple regions of the spine [43-51].

Based on widely available disc herniation literature from blind lumbar interlaminar trials, the evidence first favored caudal epidural injections, and later favored lumbar transforaminal epidural injections [4, 14-16]. Recent evidence shows similar efficacy for all 3 approaches for managing chronic disc herniation in the lumbar region [43, 45, 47, 49, 50]. However, there are also numerous publications with contradictory evidence, reporting a lack of efficacy for epidural injections for all pathologies utilizing all type of epidural injections - caudal, interlaminar, and transforaminal [52-58]. Similarly, this assessment of 2 trials [36,37], conducted in a practical nonacademic setting with proper methodology, not only provides appropriate information, but also provides guidance in the proper application of interventions to reduce chronic discogenic pain, improve function, and potentially have a patient return to the workforce. However, results based on a lack of an appropriate protocol and procedural guidance, as well as inappropriate provision of any type of intervention, specifically inclusion of those that are not cost-effective, lead to substantial expenses, harms the health care environment, and, finally, harms patients and their access.

There have not been any randomized controlled trials for lumbar transforaminal epidural injections or other trials available for caudal or lumbar interlaminar epidural injections for managing chronic discogenic pain after excluding disc herniation, facet joint pain, and sacroiliac joint pain. This assessment essentially showed an equal efficacy in the patients who responded to the initial 2 procedures; there was a much smaller nonresponsive rate with a lumbar interlaminar approach versus a caudal approach $(9 \%$ versus $35 \%$ ). Further, there was no significant differ- 
ence whether local anesthetics only were administered or if a steroid was added.

This assessment and the primary trials may be criticized for not performing provocation discographies to determine the presence of discogenic pain and/or internal disc disruption; however, based on the evidence thus far available in the literature $[4,22$, 33-38], the major structures that can cause pain are intervertebral discs (without disc herniation), facet joints, and sacroiliac joints. Since the inclusion criteria consisted of only patients without disc herniation or radiculitis, and since subsequently facet joint and sacroiliac joint pain were also excluded, the inclusion criteria are considered appropriate. In addition, it has been always claimed that patients with less than $80 \%$ pain relief after diagnostic blocks may receive any further treatments due to a lack of approval of facet or sacroiliac joint interventions, but they have been shown to respond extremely well in this setting, similar to those with disc herniation, spinal stenosis, and post lumbar surgery syndrome [4, 14-16, 36-51].

In addition, practical clinical trials with a pragmatic approach which can be applied clinically and/or shown to be valid are considered essential for evidence-based medicine and comparative effectiveness research [4, 14-16, 36-51, 59, 60]. The present analysis of 2 randomized trials of discogenic pain may be criticized for multiple deficiencies, including 2 separate randomized trials utilized in this analysis, the lack of provocation discography prior to enrolling patients into the trials, and the lack of a placebo group in either trial. However, assessing the efficacy of caudal and lumbar interlaminar approaches in a single trial compromises patient, provider, and assessor blinding. Placebo design for interventional techniques is extremely difficult and multiple previous designs have been criticized for their inappropriate utilization in assessing epidural injections including caudal, interlaminar, and transformational approaches [[4, 14-16]. Unlike epidural injections performed in managing disc herniation, there are no placebo trials available for discogenic pain either performed blindly or with fluoroscopy with any of the approaches. Multiple issues related to placebo-controlled trials are based on ample evidence that inactive substances, when injected into active structures, invariably result in various types of clinical effects, as well as placebo and nocebo effects $[3,4,36-50,53,58-75]$. In addition, local anesthetics also have shown long-term improvement or response that is similar to steroids in clinical and experimental settings [4, 14-16, 36-51, 76-78]. However, 2 appropriate placebo-designed trials have been described for interventional techniques $[79,80]$. Thus, it is not only essential, but also mandatory, to design appropriate placebo studies in in- terventional pain management settings by injecting inactive solutions into inactive structures. Further, it is crucial to determine the improvement from baseline to follow-up periods rather than depending on between-group or between-trial differences and also not to consider either short-acting or even long-acting local anesthetics as placebos.

\section{Conclusion}

This assessment shows that the 2 trials which included patients who failed to respond positively to the diagnostic criteria of $80 \%$ pain relief threshold responded with significant improvement in $78 \%$ or $70 \%$ with local anesthetic only or with a steroid in the lumbar interlaminar trial; whereas, the response rate was $84 \%$ and $73 \%$ in the caudal trial.

\section{Abbreviations}

NRS: numeric rating pain scale; ODI: Oswestry Disability Index; DRG: dorsal root ganglia; TNF: tumor necrosis factor; IL-6: interleukin-6; NGF: nerve growth factor; IRB: Institutional Review Board; NCT: National Clinical Trial; CONSORT: Consolidated Standards of Reporting Trials

\section{Acknowledgments}

The authors wish to thank Tom Prigge, MA, and Laurie Swick, BS for manuscript review; and Tonie M. Hatton and Diane E. Neihoff, transcriptionists, for their assistance in preparation of this manuscript.

\section{Disclaimer}

There was no external financial support. The support was from the first author's practice.

\section{Competing interests}

Dr. Benyamin is a consultant and lecturer for Boston Scientific and Kimberly Clark.

\section{References}

1. US Burden of Disease Collaborators. The state of US health, 1990-2010: burden of diseases, injuries, and risk factors. Jama. 2013; 310: 591-608.

2. Gaskin DJ, Richard P. The economic costs of pain in the United States. J Pain. 2012; 13: 715-24.

3. Martin BI, Turner JA, Mirza SK, Lee MJ, Comstock BA, Deyo RA. Trends in health care expenditures, utilization, and health status among US adults with spine problems, 1997-2006. Spine (Phila Pa 1976). 2009; 34: 2077-84.

4. Manchikanti L, Abdi S, Atluri S, Benyamin RM, Boswell MV, Buenaventura $\mathrm{RM}$, et al. An update of comprehensive evidence-based guidelines for interventional techniques in chronic spinal pain. Part II: guidance and recommendations. Pain Physician. 2013; 16: S49-283.

5. Freburger JK, Holmes GM, Agans RP, Jackman AM, Darter JD, Wallace AS, et al. The rising prevalence of chronic low back pain. Arch Intern Med. 2009; 169: 251-8.

6. Deyo RA, Mirza SK, Turner JA, Martin BI. Overtreating chronic back pain: time to back off? J Am Board Fam Med. 2009; 22: 62-8.

7. Rajaee SS, Bae HW, Kanim LE, Delamarter RB. Spinal fusion in the United States: analysis of trends from 1998 to 2008. Spine (Phila Pa 1976). 2008; 37: 67-76.

8. Deyo RA, Gray DT, Kreuter W, Mirza S, Martin BI. United States trends in lumbar fusion surgery for degenerative conditions. Spine (Phila Pa 1976). 2005; 30: 1441-5; discussion 6-7. 
9. Manchikanti L, Abdi S, Atluri S, Balog CC, Benyamin RM, Boswell MV, et al. American Society of Interventional Pain Physicians (ASIPP) guidelines for responsible opioid prescribing in chronic non-cancer pain: Part 2--guidance. Pain Physician. 2012; 15: S67-116.

10. Manchikanti L, Falco FJ, Singh V, Pampati V, Parr AT, Benyamin RM, et al. Utilization of interventional techniques in managing chronic pain in the Medicare population: analysis of growth patterns from 2000 to 2011. Pain Physician. 2012; 15: E969-82.

11. Manchikanti L, Helm Ii S, Singh V, Hirsch JA. Accountable interventional pain management: a collaboration among practitioners, patients, payers, and government. Pain Physician. 2013; 16: E635-70.

12. Zodet MW, Stevans JM. The 2008 prevalence of chiropractic use in the US adult population. J Manipulative Physiol Ther. 2012; 35: 580-8

13. van Middelkoop M, Rubinstein SM, Kuijpers T, Verhagen AP, Ostelo R, Koes BW, et al. A systematic review on the effectiveness of physical and rehabilitation interventions for chronic non-specific low back pain. European spine journal : official publication of the European Spine Society, the European Spinal Deformity Society, and the European Section of the Cervical Spine Research Society. 2011; 20: 19-39.

14. Parr AT, Manchikanti L, Hameed H, Conn A, Manchikanti KN, Benyamin RM, et al. Caudal epidural injections in the management of chronic low back pain: a systematic appraisal of the literature. Pain Physician. 2012; 15: E159-98.

15. Benyamin RM, Manchikanti L, Parr AT, Diwan S, Singh V, Falco FJ, et al. The effectiveness of lumbar interlaminar epidural injections in managing chronic low back and lower extremity pain. Pain Physician. 2012; 15: E363-404.

16. Manchikanti L, Buenaventura RM, Manchikanti KN, Ruan X, Gupta S, Smith $\mathrm{HS}$, et al. Effectiveness of therapeutic lumbar transforaminal epidural steroid injections in managing lumbar spinal pain. Pain Physician. 2012; 15: E199-245.

17. Tosteson AN, Skinner JS, Tosteson TD, Lurie JD, Andersson GB, Berven S, et al. The cost effectiveness of surgical versus nonoperative treatment for lumbar disc herniation over two years: evidence from the Spine Patient Outcomes Research Trial (SPORT). Spine (Phila Pa 1976). 2008; 33: 2108-15.

18. Tosteson AN, Tosteson TD, Lurie JD, Abdu W, Herkowitz H, Andersson G, et al. Comparative effectiveness evidence from the spine patient outcomes research trial: surgical versus nonoperative care for spinal stenosis, degenerative spondylolisthesis, and intervertebral disc herniation. Spine (Phila Pa 1976). 2011; 36: 2061-8

19. Schoenfeld AJ, Carey PA, Cleveland AW, 3rd, Bader JO, Bono CM. Patient factors, comorbidities, and surgical characteristics that increase mortality and complication risk after spinal arthrodesis: a prognostic study based on 5,887 patients. The spine journal : official journal of the North American Spine Society. 2013; 13: 1171-9.

20. Malik KM, Cohen SP, Walega DR, Benzon HT. Diagnostic criteria and treatment of discogenic pain: a systematic review of recent clinical literature. The spine journal : official journal of the North American Spine Society. 2013; 13: $1675-89$

21. Peng B, Fu X, Pang X, Li D, Liu W, Gao C, et al. Prospective clinical study on natural history of discogenic low back pain at 4 years of follow-up. Pain Physician. 2012; 15: 525-32.

22. Manchikanti L, Benyamin RM, Singh V, Falco FJ, Hameed H, Derby R, et al. An update of the systematic appraisal of the accuracy and utility of lumbar discography in chronic low back pain. Pain Physician. 2013; 16: SE55-95.

23. Bogduk N, Aprill C, Derby R. Lumbar discogenic pain: state-of-the-art review. Pain Med. 2013; 14: 813-36.

24. Mixter WJ. Rupture Of The Lumbar Intervertebral Disk: An Etiologic Factor For So-Called "Sciatic" Pain. Ann Surg. 1937; 106: 777-87.

25. Keyes DC, Compere EL. The normal and pathological physiology of the nucleus pulposus of the intervertebral disc: an anatomical, clinical and experimental study. The Journal of bone and joint surgery American volume. 1932; 14: 897-938.

26. Manchikanti L, Pampati V, Falco FJ, Hirsch JA. Assessment of the growth of epidural injections in the medicare population from 2000 to 2011. Pain Physician. 2013; 16: E349-64.

27. Carragee EJ, Deyo RA, Kovacs FM, Peul WC, Lurie JD, Urrutia G, et al. Clinical research: is the spine field a mine field? Spine (Phila Pa 1976). 2009; 34: 423-30.

28. Mirza SK, Deyo RA. Systematic review of randomized trials comparing lumbar fusion surgery to nonoperative care for treatment of chronic back pain. Spine (Phila Pa 1976). 2007; 32: 816-23.

29. Jacobs WC, van der Gaag NA, Kruyt MC, Tuschel A, de Kleuver M, Peul WC, et al. Total disc replacement for chronic discogenic low back pain: a Cochrane review. Spine (Phila Pa 1976). 2013; 38: 24-36.

30. Health Technology Assessment, Washington State Health Care Authority. Spinal fusion for treatment of degenerative disc disease affecting the lumbar spine. Washington Health Technology Assessment. Rockville, MD: Agency for Healthcare Research and Quality. 2006.

31. Mirza SK, Deyo RA, Heagerty PJ, Turner JA, Martin BI, Comstock BA. One-year outcomes of surgical versus nonsurgical treatments for discogenic back pain: a community-based prospective cohort study. The spine journal : official journal of the North American Spine Society. 2013; 13: 1421-33.

32. Crock HV. A reappraisal of intervertebral disc lesions. Med J Aust. 1970; 1: 983-9.

33. Schwarzer AC, Aprill CN, Derby R, Fortin J, Kine G, Bogduk N. The prevalence and clinical features of internal disc disruption in patients with chronic low back pain. Spine (Phila Pa 1976). 1995; 20: 1878-83.
34. DePalma MJ, Ketchum JM, Saullo T. What is the source of chronic low back pain and does age play a role? Pain Med. 2011; 12: 224-33.

35. Manchikanti L, Singh V, Pampati V, Damron KS, Barnhill RC, Beyer C, et al. Evaluation of the relative contributions of various structures in chronic low back pain. Pain Physician. 2001; 4: 308-16.

36. Manchikanti L, Cash KA, McManus CD, Pampati V. Fluoroscopic caudal epidural injections in managing chronic axial low back pain without disc herniation, radiculitis, or facet joint pain. Journal of pain research. 2012; 5: 381-90.

37. Manchikanti L, Cash KA, McManus CD, Pampati V, Benyamin RM. A randomized, double-blind, active-controlled trial of fluoroscopic lumbar interlaminar epidural injections in chronic axial or discogenic low back pain: results of 2-year follow-up. Pain Physician. 2013; 16: E491-504.

38. Manchikanti L, Cash KA, Pampati V, Malla Y. Two-year follow-up results of fluoroscopic cervical epidural injections in chronic axial or discogenic neck pain: a randomized, double-blind, controlled trial. Int J Med Sci. 2014; 11: 309-20.

39. Simopoulos TT, Manchikanti L, Singh V, Gupta S, Hameed H, Diwan S, et al. A systematic evaluation of prevalence and diagnostic accuracy of sacroiliac joint interventions. Pain Physician. 2012; 15: E305-44.

40. Falco FJ, Manchikanti L, Datta S, Sehgal N, Geffert S, Onyewu O, et al. An update of the systematic assessment of the diagnostic accuracy of lumbar facet joint nerve blocks. Pain Physician. 2012; 15: E869-907.

41. Manchukonda R, Manchikanti KN, Cash KA, Pampati V, Manchikanti L. Facet joint pain in chronic spinal pain: an evaluation of prevalence and false-positive rate of diagnostic blocks. J Spinal Disord Tech. 2007; 20: 539-45.

42. Manchikanti L, Boswell MV, Singh V, Pampati V, Damron KS, Beyer CD. Prevalence of facet joint pain in chronic spinal pain of cervical, thoracic, and lumbar regions. BMC Musculoskelet Disord. 2004; 5: 15

43. Manchikanti L, Singh V, Cash KA, Pampati V, Damron KS, Boswell MV. Effect of fluoroscopically guided caudal epidural steroid or local anesthetic injections in the treatment of lumbar disc herniation and radiculitis: a randomized, controlled, double blind trial with a two-year follow-up. Pain Physician. 2012; 15: 273-86

44. Manchikanti L, Cash KA, McManus CD, Pampati V, Fellows B. Results of 2-year follow-up of a randomized, double-blind, controlled trial of fluoroscopic caudal epidural injections in central spinal stenosis. Pain Physician. 2012; 15: 371-84

45. Manchikanti L, Singh V, Cash KA, Pampati V, Falco FJ. A randomized, double-blind, active-control trial of the effectiveness of lumbar interlaminar epidural injections in disc herniation. Pain Physician. 2014; 17: E61-74.

46. Manchikanti L, Cash KA, McManus CD, Damron KS, Pampati V, Falco FJ. A randomized, double-blind controlled trial of lumbar interlaminar epidural injections in central spinal stenosis: 2-year follow-up. Int J Phys Med Rehab. 2014; 2: 1000179 .

47. Manchikanti L, Cash KA, Pampati V, Falco FJ. Transforaminal epidural injections in chronic lumbar disc herniation: a randomized, double-blind, active-control trial. Pain Physician. 2014; 17: E489-501.

48. Manchikanti L, Singh V, Cash KA, Pampati V, Datta S. Fluoroscopic caudal epidural injections in managing post lumbar surgery syndrome: two-year results of a randomized, double-blind, active-control trial. Int J Med Sci. 2012; 9: 582-91.

49. Manchikanti L, Benyamin RM, Falco FJ, Kaye AD, Hirsch JA. Do Epidural Injections Provide Short- and Long-term Relief for Lumbar Disc Herniation? A Systematic Review. Clin Orthop Relat Res. 2014.

50. Chang-Chien GC, Knezevic NN, McCormick Z, Chu SK, Trescot AM, Candido KD. Transforaminal versus interlaminar approaches to epidural steroid injections: a systematic review of comparative studies for lumbosacral radicular pain. Pain Physician. 2014; 17: E509-24.

51. Manchikanti L, Cash KA, Pampati V, Wargo BW, Malla Y. A randomized, double-blind, active control trial of fluoroscopic cervical interlaminar epidural injections in chronic pain of cervical disc herniation: results of a 2-year follow-up. Pain Physician. 2013; 16: 465-78. 24077193

52. Pinto RZ, Maher CG, Ferreira ML, Hancock M, Oliveira VC, McLachlan AJ, et al. Epidural corticosteroid injections in the management of sciatica: a systematic review and meta-analysis. Annals of internal medicine. 2012; 157: 865-77.

53. Staal JB, de Bie R, de Vet HC, Hildebrandt J, Nelemans P. Injection therapy for subacute and chronic low-back pain. The Cochrane database of systematic reviews. 2008: CD001824.

54. Carette S, Marcoux S, Truchon R, Grondin C, Gagnon J, Allard Y, et al. A controlled trial of corticosteroid injections into facet joints for chronic low back pain. N Engl J Med. 1991; 325: 1002-7.

55. Iversen T, Solberg TK, Romner B, Wilsgaard T, Twisk J, Anke A, et al. Effect of caudal epidural steroid or saline injection in chronic lumbar radiculopathy: multicentre, blinded, randomised controlled trial. Bmj. 2011; 343: d5278.

56. Karppinen J, Malmivaara A, Kurunlahti M, Kyllonen E, Pienimaki T, Nieminen $\mathrm{P}$, et al. Periradicular infiltration for sciatica: a randomized controlled trial. Spine (Phila Pa 1976). 2001; 26: 1059-67.

57. Friedly JL, Comstock BA, Turner JA, Heagerty PJ, Deyo RA, Sullivan SD, et al. A randomized trial of epidural glucocorticoid injections for spinal stenosis. N Engl J Med. 2014; 371: 11-21.

58. Chou R, Huffman L. Guideline for the Evaluation and Management of Low Back Pain: Evidence Review. American Pain Society, Glenview, IL, 2009. http://www.americanpainsociety.org/uploads/pdfs/LBPEvidRev.pdf 
59. Hotopf M. The pragmatic randomized controlled trial. Adv Psychiatr Treat. 2002; 8: 326-33.

60. Roland M, Torgerson DJ. What are pragmatic trials? Bmj. 1998; 316: 285

61. Howick J, Friedemann C, Tsakok M, Watson R, Tsakok T, Thomas J, et al. Are treatments more effective than placebos? A systematic review and meta-analysis. PLoS One. 2013; 8: e62599.

62. Kaptchuk TJ, Friedlander E, Kelley JM, Sanchez MN, Kokkotou E, Singer JP, et al. Placebos without deception: a randomized controlled trial in irritable bowel syndrome. PLoS One. 2010; 5: e15591.

63. Petersen GL, Finnerup NB, Colloca L, Amanzio M, Price DD, Jensen TS, et al. The magnitude of nocebo effects in pain: a meta-analysis. Pain. 2014; 155: 1426-34.

64. Bingel U. Avoiding nocebo effects to optimize treatment outcome. Jama. 2014; 312: 693-4.

65. Colloca L, Finniss D. Nocebo effects, patient-clinician communication, and therapeutic outcomes. Jama. 2012; 307: 567-8

66. Hrobjartsson A, Gotzsche PC. Is the placebo powerless? An analysis of clinical trials comparing placebo with no treatment. N Engl J Med. 2001; 344: 1594-602.

67. Manchikanti L, Giordano J, Fellows B, Hirsch JA. Placebo and nocebo in interventional pain management: a friend or a foe--or simply foes? Pain Physician. 2011; 14: E157-75.

68. Chou R, Atlas SJ, Loeser JD, Rosenquist RW, Stanos SP. Guideline warfare over interventional therapies for low back pain: can we raise the level of discourse? J Pain. 2011; 12: 833-9.

69. Manchikanti L, Benyamin RM, Falco FJ, Caraway DL, Datta S, Hirsch JA. Guidelines warfare over interventional techniques: is there a lack of discourse or straw man? Pain Physician. 2012; 15: E1-E26.

70. Bhatia MT, Parikh CJ. Epidural-saline therapy in lumbosciatic syndrome. J Indian Med Assoc. 1966; 47: 537-42.

71. Gupta AK, Mital VK, Azmi RU. Observations on the management of lumbosciatic syndrome (sciatica) by epidural saline injection. J Indian Med Assoc. 1970; 54: 194-6.

72. Wittenberg RH, Greskotter KR, Steffen R, Schoenfeld BL. [Is epidural injection treatment with hypertonic saline solution in intervertebral disk displacement useful? (The effect of $\mathrm{NaCl}$ solution on intervertebral disk tissue)]. Z Orthop Ihre Grenzgeb. 1990; 128: 223-6.

73. Pasqualucci A, Varrassi G, Braschi A, Peduto VA, Brunelli A, Marinangeli F, et al. Epidural local anesthetic plus corticosteroid for the treatment of cervical brachial radicular pain: single injection versus continuous infusion. The Clinical journal of pain. 2007; 23: 551-7.

74. Mao J, Chen LL. Systemic lidocaine for neuropathic pain relief. Pain. 2000; 87: 7-17.

75. Arner S, Lindblom U, Meyerson BA, Molander C. Prolonged relief of neuralgia after regional anesthetic blocks. A call for further experimental and systematic clinical studies. Pain. 1990; 43: 287-97.

76. Bicket MC, Gupta A, Brown CHt, Cohen SP. Epidural injections for spinal pain: a systematic review and meta-analysis evaluating the "control" injections in randomized controlled trials. Anesthesiology. 2013; 119: 907-31.

77. Sato C, Sakai A, Ikeda Y, Suzuki H, Sakamoto A. The prolonged analgesic effect of epidural ropivacaine in a rat model of neuropathic pain. Anesth Analg. 2008; 106: 313-20.

78. Tachihara H, Sekiguchi M, Kikuchi S, Konno S. Do corticosteroids produce additional benefit in nerve root infiltration for lumbar disc herniation? Spine (Phila Pa 1976). 2008; 33: 743-7.

79. Gerdesmeyer L, Wagenpfeil S, Birkenmaier C, Veihelmann A, Hauschild M, Wagner K, et al. Percutaneous epidural lysis of adhesions in chronic lumbar radicular pain: a randomized, double-blind, placebo-controlled trial. Pain Physician. 2013; 16: 185-96.

80. Ghahreman A, Ferch R, Bogduk N. The efficacy of transforaminal injection of steroids for the treatment of lumbar radicular pain. Pain Med. 2010; 11: $1149-68$. 